\title{
Fortification of Cheddar cheese with vitamin D does not alter cheese flavor perception
}

\author{
B. Ganesan, ${ }^{1}$ C. Brothersen, and D. J. McMahon \\ Western Dairy Center, Department of Nutrition, Dietetics and Food Sciences, Utah State University, Logan 84322
}

\begin{abstract}
Currently, dietary guidelines for vitamin D consumption are under review, considering new information that $>50 \%$ of the US population is vitamin D deficient, and may lead to a recommendation of a higher dietary intake of this vitamin. Vitamin D fortification of cheese aims to improve the current availability of fortified dairy foods beyond liquid milk. However, cheese is susceptible to undesirable flavor changes during longterm cheese ripening, and cheese bacteria and enzymes may degrade added vitamins. To test the retention of vitamin $\mathrm{D}_{3}$ in Cheddar cheese curd, cheese milk was fortified initially during manufacture at a level of 150 $\mathrm{IU} /$ serving, using commercial sources that contained vitamin $\mathrm{D}_{3}$ in powder, oil, or emulsion form, with and without homogenization of the fortified milk. When fortification was done directly to the cheese milk, we found that more than $80 \%$ vitamin $\mathrm{D}_{3}$ was retained in cheese curd, irrespective of homogenization or form of fortification. Further, Cheddar cheese was fortified with the emulsion form of vitamin $\mathrm{D}_{3}$ directly in cheese milk at 200 and $400 \mathrm{IU} /$ serving to test stability and flavor changes. Vitamin $\mathrm{D}_{3}$ fortified in this manner was stable for up to 9 mo in Cheddar cheese. Consumer acceptance and descriptive analysis of flavor profiles of cheese were also conducted and showed that vitamin $\mathrm{D}_{3}$ fortified cheeses were equally liked by consumers, and cheese taste and flavor remained unaltered with vitamin $\mathrm{D}_{3}$ addition even after aging for 9 mo.
\end{abstract}

Key words: Cheddar cheese, vitamin D, flavor, retention

\section{INTRODUCTION}

Vitamin D is a class of fat-soluble vitamins widely recognized for its importance in skeletal health (Ceglia, 2009). The major forms of the vitamin class responsible for human health benefits are ergocalciferol $\left(\mathbf{D}_{\mathbf{2}}\right)$ and cholecalciferol $\left(\mathbf{D}_{3}\right)$. These vitamin D forms are con-

Received November 18, 2010.

Accepted March 28, 2011.

${ }^{1}$ Corresponding author: g.balsu@usu.edu sidered to be inactive until they are converted to their biologically active form, 1,25-dihydroxy vitamin $\mathrm{D}_{3}$, in the liver or kidney (Holick, 1995), which then promotes calcium and phosphorous absorption and aids bone mineralization and muscle strength. More recently, vitamin $\mathrm{D}_{3}$ has been shown to have preventive effects against certain types of cancer (Bouillon et al., 2006). This vitamin class' mechanism of action resembles that of hormones and, hence, the vitamin D class is collectively classified as a prohormone (Bikle, 1997).

Of the 2 biologically beneficial forms, vitamin $\mathrm{D}_{3}$ is readily synthesized by the human body during exposure to sunlight of UV index $>3$ for 5 to 30 min (Holick, 1995), whereas vitamin $D_{2}$ is synthesized only by plants and fungi (Ricardo, 1986). In subtropical areas of the world, sunlight exposure alone is insufficient to produce adequate vitamin D throughout the year (Holick, 1995). Populations in these areas need a vitamin D-fortified diet to achieve adequate levels for health benefits, which, for dairy foods, has mainly been through fortification of fluid milk, in which 1 cup of milk provides $100 \mathrm{IU}$ of vitamin $\mathrm{D}_{3}$. Incidence of low serum vitamin D levels in young adults who were presumed to have a healthy diet has been observed to be more frequent than expected (Heidi Wengreen, Utah State University, Logan, personal communication). This observation was confirmed by a recent review of vitamin D deficiency prevalence in North America that recommended a 2.5fold dietary increase to achieve adequate intake (Hanley and Davison, 2005).

In order to provide sufficient levels of serum vitamin D in North American adults, the dietary intake level of vitamin D for optimal health is currently under scrutiny. Initially, the vitamin $\mathrm{D}$ reference daily intake level was set at $400 \mathrm{IU}$ in 1968 by the Institute of Medicine's Food and Nutrition Board (US FDA, 2007; Institute of Medicine, 2009). In 1999, the Food and Nutrition Board established a dietary reference intake level of 200 IU per day for people up to $50 \mathrm{yr}$ of age and increasing amounts for older persons, assuming absence of adequate sunlight exposure (Institute of Medicine, Food and Nutrition Board, 1999). Research efforts that have since focused on vitamin D's biological role along with evidence from more recent clinical trials recommended 
a 2-fold higher level of intake, even for pediatric and adolescent populations (Holick, 2007; Vieth et al., 2007). In light of new evidence, the Food and Nutrition Board has recently designated an expert committee to revise the recommendations for vitamin D dietary intake levels (Institute of Medicine, Food and Nutrition Board, 2010).

Other than fish and marine products, foods normally consumed by humans are low in vitamin $\mathrm{D}_{3}$ content and need fortification to adequately supplement our daily needs. Fish contains approximately 120 to $500 \mathrm{IU}$ of vitamin $\mathrm{D}_{3}$ per 3-oz serving (Holden, 2009), almost 50 to $200 \%$ of the recommended daily intake level, as opposed to $<25 \%$ in unfortified grains, meats, vegetables, and breakfast cereal. Unfortified whole milk and cheese provide only $1 \%$ of the daily value of vitamin $D$ (Holden, 2009), which is insufficient for proper nutrition. Among dairy foods, cheese is widely consumed in various forms across different populations of the United States. Cheddar cheese is rich in vitamins A and $\mathrm{B}$ (Holden, 2009), and fortification with vitamin $\mathrm{D}_{3}$ would increase its acceptance as a nutritious food that is rich in protein, vitamins, and minerals. Cheese can be relatively easily fortified with vitamin $\mathrm{D}_{3}$ to provide up to $100 \%$ daily value in the diet, as it has a higher milk fat content than liquid milk, which aids inclusion of fat-soluble vitamins.

Effective retention in curd and long-term stability of vitamin $\mathrm{D}_{3}$ in cheese are essential for uniform nutrient delivery to the consumer. Previous studies show that about 85 to $90 \%$ of added vitamin D is effectively retained in Cheddar cheese (Kazmi et al., 2007; Wagner et al., 2008), except in one study (Banville et al., 2000) that reported recovery ranging between 40 and 50\%. The differences in retention between studies are likely due to different forms of vitamin $\mathrm{D}$ used for fortification. However, approximately $90 \%$ retention has been achieved and suggests that fortification of cheese is feasible.

The ability of bacteria to metabolize vitamin $\mathrm{D}_{3}$ is uncharacterized but may contribute to a reduction of fortified vitamin $\mathrm{D}_{3}$ levels. Additionally, the physicochemical environment of cheese, such as lower $\mathrm{pH}$, higher salt, longer storage, and further thermal processing, may also reduce the stability of added vitamin D. However, vitamin $\mathrm{D}_{3}$ appears to be stable in cheese during both short-term (Banville et al., 2000) and long-term storage (Kazmi et al., 2007; Wagner et al., 2008). Upreti et al. (2002) reported a $25 \%$ reduction in vitamin $\mathrm{D}_{3}$ content during thermal treatment of processed cheese at $232^{\circ} \mathrm{C} / 5$ min, whereas Wagner et al. (2008) reported no thermal loss in Cheddar cheese for the same heat treatment. Hence, stability to thermal treatment varies by type of cheese and manufacturing conditions, whereas storage appears to have no effect on vitamin $\mathrm{D}_{3}$ stability in cheese.

The inclusion of a novel chemical component may affect cheese flavor, which is a complex attribute that arises from a variety of volatile and nonvolatile organic compounds (Mulder, 1952; Fox and Wallace, 1997). These compounds are produced by enzymes of bacteria that degrade casein into peptides and amino acids and further metabolize the amino acid substrates into compounds that contribute to cheese flavor (Fox et al., 1995). Lipolysis and subsequent release of fatty acids that are further metabolized by bacteria also play a role in cheese flavor. Physicochemical alterations to cheese such as age, temperature, $\mathrm{pH}$, salt level, and redox potential all cumulatively influence bacterial metabolism and consequently the types of compounds produced. Any external component added may modify one or more of these physicochemical attributes and eventually influence cheese flavor.

Only a limited number of studies have documented the effect of vitamin $\mathrm{D}$ fortification on cheese flavor. These efforts mainly addressed successful cheese fortification using different methods for retaining fortified components and for providing even distribution in cheese curd (Wagner et al., 2008). Banville et al. (2000) found the flavor perception of vitamin D-fortified Cheddar cheese to be similar to that of unfortified cheese flavor at 2 mo of aging. Upreti et al. (2002) reported similar results for fortified processed cheese. However, to our knowledge, the effect of vitamin $\mathrm{D}_{3}$ fortification on flavor acceptability of cheese during long-term aging (>3 mo) has not been documented.

In this study, our objectives were to identify vitamin $\mathrm{D}$ retention in cheese curd with minimal loss using commercial sources, select an appropriate source of vitamin $\mathrm{D}$ for fortification, and further study whether vitamin $\mathrm{D}$ is lost during cheese aging.

\section{MATERIALS AND METHODS}

Preliminary studies were conducted to determine vitamin $\mathrm{D}$ retention in cheese curd, followed by a longterm aging study to understand scalability and vitamin D stability during aging. In order to understand the role of vitamin $\mathrm{D}_{3}$ in altering cheese flavor, we fortified Cheddar cheese with vitamin $\mathrm{D}_{3}$ at 2 different levels, 200 and $400 \mathrm{IU} /$ serving. Four trials were conducted on separate days using $10-\mathrm{kg}$ batches of milk to make vitamin D-fortified cheeses for preliminary studies. Each batch of cheese milk was individually fortified with the respective source of vitamin $\mathrm{D}$ on the day of manufacture. Long-term aging cheeses including controls were manufactured in 2 replicates on different days with different batches of milk. In all stages of the study, vitamin 
D concentrations in cheese milk, curd, whey, and cheese were determined using liquid chromatography (AOAC, 2006; method 952.29), as recommended by the FDA, analyzed by O'Neal Scientific Services (St. Louis, MO).

\section{Cheese Manufacture}

Fresh cow milk for cheese making was obtained from Utah State University's George B. Caine Dairy Research and Teaching Center (Wellsville, UT). The starter culture used consisted of a blend of Lactococcus lactis ssp. lactis and cremoris strains (DVS850; Chr. Hansen Inc., Milwaukee, WI) in frozen pellet form. Chymosin rennet (double strength Maxiren, 650 international milk clotting units $/ \mathrm{mL}$ ) and annatto color (single strength) were obtained from DSM Food Specialties USA Inc. (Eagleville, PA). Three different preparations of vitamin $\mathrm{D}_{3}$ available in emulsion $(40,000 \mathrm{IU} / \mathrm{mL}$; Continental Custom Ingredients Inc., West Chicago, IL), powder (100,000 IU/g; BASF, Mount Olive, NJ), and oil $(1,000,000 \mathrm{IU} / \mathrm{g} ; \mathrm{BASF})$ forms were used in preliminary studies. Vitamin $\mathrm{D}_{3}$ used for fortifying cheese milk for long-term aging was in emulsion form.

\section{Assessment of Vitamin D Retention in Curd}

Requisite amounts of the emulsion, powder, or oil form of vitamin $\mathrm{D}$ to achieve a final vitamin $\mathrm{D}$ level of $150 \mathrm{IU} /$ serving, assuming $100 \%$ retention, were prehomogenized (dual-stage homogenization, 13.8 and 3.5 $\mathrm{MPa}$ at $\left.60^{\circ} \mathrm{C}\right)$ with milk $(\sim 2 \mathrm{~kg})$, which was then used as a stock, of which 0.125 or $0.25 \mathrm{~kg}$ was added with vigorous agitation to the cheese milk, depending on the required fortification level. For the nonhomogenized treatments, vitamin D powder, oil, and emulsion forms were added directly to the cheese milk in the cheese vat with admixing. After ripening (45 min), calcium chloride $(18 \mathrm{~mL})$, annatto coloring $(12 \mathrm{~mL})$, and chymosin $(12 \mathrm{~mL})$ were consecutively stirred into cheese milk. The set curd was cut with $16-\mathrm{mm}$ curd knives, healed, and then cooked $\left(31\right.$ to $\left.39^{\circ} \mathrm{C} / 35 \mathrm{~min}\right)$ prior to whey draining $(\mathrm{pH}$ 6.3). The curd was allowed to mat together, cut into slabs, and cheddared. At $\mathrm{pH} 5.4$, the curd was milled, salted $(272 \mathrm{~g} / \mathrm{kg}$ curd, 3 applications 5 min apart), pressed (100 kPa) overnight into 9.1-kg blocks, vacuum-packaged, and stored at $6^{\circ} \mathrm{C}$.

\section{Vitamin D Stability During Long-Term Aging}

Cheddar cheese for the long-term aging study was manufactured at the Gary Haight Richardson Dairy Products Laboratory, Utah State University, using previously described procedures (Martini et al., 2009) with appropriate modifications. Briefly, milk at an initial $\mathrm{pH}$ of $6.7 \pm 0.05$ was standardized to a protein:fat ratio of 0.83 and pasteurized $\left(73^{\circ} \mathrm{C}, 15 \mathrm{~s}\right)$. Starter culture $(17 \mathrm{~g})$ was added to milk (113 $\mathrm{kg})$ at $31^{\circ} \mathrm{C}$, followed by addition of sufficient vitamin $\mathrm{D}$ to the milk to obtain nominal vitamin $\mathrm{D}$ levels in the cheese of 0 (control), 200 , and $400 \mathrm{IU} /$ serving. The amount of vitamin D source to be added was based on retention information obtained in the preliminary studies.

\section{Sensory Panels}

Consumer and descriptive sensory panels were conducted to assess acceptance and sensory attributes respectively of vitamin $\mathrm{D}$ cheeses. Training procedures and conduct of sensory panels have been described previously (Martini et al., 2009). Three samples with a replicate each were presented to panelists at room temperature in a completely randomized block design. Consumer panels included 118 participants, who scored the cheeses on a 9-point hedonic scale to denote degree of liking, where $1=$ dislike extremely, $2=$ dislike very much, $3=$ dislike moderately, $4=$ dislike slightly, $5=$ neither like nor dislike, $6=$ like slightly, $7=$ like moderately, $8=$ like very much, and $9=$ like extremely. For descriptive sensory analysis, 8 panelists were included and all had undergone at least $50 \mathrm{~h}$ of training before participation. The panelists were requested to note 5 basic tastes (bitter, salty, sour, sweet, and umami) and 14 flavor attributes in the cheeses (brothy, buttery, cooked, fishy, fruity, lactone/fatty acid, metallic, nutty, oxidized, pineappley, rancid, rosy/floral, sulfur, and whey), and rate each of these attributes on a 15-point categorical scale. Sensory data were collected using SIMS 2000 software (Morristown, NJ) and analyzed using SAS 9.1.3 (SAS Institute, Cary, NC).

\section{Statistical Analysis}

Differences in proximate composition of cheese and retention of vitamin $\mathrm{D}$ in cheese were compared by a 2-way ANOVA in JMP 7 statistical software (SAS Institute). Repeated-measures ANOVA with autoregressive correlation structure was used to analyze the effect of vitamin D addition and cheese age on liking scores.

\section{RESULTS AND DISCUSSION}

Initial experiments were done to determine the best form of vitamin $\mathrm{D}_{3}$ to use and to optimize Cheddar cheese manufacture parameters using $10 \mathrm{~kg}$ of milk with a targeted final vitamin $\mathrm{D}_{3}$ level of $150 \mathrm{IU} /$ serving in curd. All forms of vitamin D were added directly to the cheese milk before ripening. Analysis of the vitamin $\mathrm{D}_{3}$ content of these cheeses showed that irrespective 
Table 1. Vitamin $\mathrm{D}_{3}$ recovery in cheese curd and proximate composition of Cheddar cheeses (made from 10 $\mathrm{kg}$ of milk) fortified with different sources to final vitamin $\mathrm{D}_{3}$ level of $150 \mathrm{IU} /$ serving (values are reported as mean $\pm \mathrm{SD})$

\begin{tabular}{llcccc}
\hline & & \multicolumn{2}{c}{ Proximate analysis of cheese $(\mathrm{n}=2)$} \\
\cline { 3 - 6 } $\begin{array}{l}\text { Vitamin } \mathrm{D}_{3} \\
\text { form }\end{array}$ & Treatment & $\begin{array}{c}\text { Vitamin } \mathrm{D}_{3} \\
\text { recovery }(\%) \\
(\mathrm{n}=2)\end{array}$ & $\begin{array}{c}\text { Moisture } \\
(\%)\end{array}$ & $\begin{array}{c}\text { Fat } \\
(\%)\end{array}$ & $\mathrm{pH}$ \\
\hline Emulsion & Unhomogenized & $93 \pm 4.7$ & $38.5 \pm 0.2$ & $32.3 \pm 1.1$ & $4.95 \pm 0.04$ \\
& Homogenized & $81 \pm 2.9$ & $38.5 \pm 0.3$ & $32.0 \pm 1.4$ & $5.00 \pm 0.04$ \\
Oil & Unhomogenized & $120 \pm 13.6$ & $38.8 \pm 0.8$ & $32.0 \pm 0.7$ & $4.95 \pm 0.01$ \\
& Homogenized & $98 \pm 2.4$ & $38.6 \pm 1.0$ & $32.0 \pm 1.4$ & $5.00 \pm 0.05$ \\
Powder & Unhomogenized & $117 \pm 5.1$ & $39.0 \pm 0.7$ & $32.0 \pm 1.4$ & $4.95 \pm 0.01$ \\
& Homogenized & $98 \pm 6.7$ & $39.1 \pm 0.5$ & $31.5 \pm 2.1$ & $4.97 \pm 0.02$ \\
\hline
\end{tabular}

of form, when the vitamin D preparation was not homogenized into milk before addition to the cheese vat, the retention of vitamin $\mathrm{D}_{3}$ in cheese was consistently $>95 \%$ and provided cheeses with similar proximate composition independent of vitamin $\mathrm{D}_{3}$ source (Table 1). Further experiments with the emulsion and powder forms in $113 \mathrm{~kg}$ of milk for fortification up to $400 \mathrm{IU} /$ serving showed that the powder form was retained less than the emulsion form when they were added to the cheese milk before renneting (Table 2; Figure 1, top panel). Recovery of vitamin $\mathrm{D}_{3}$ was similar in Cheddar cheeses fortified at 200 and $400 \mathrm{IU} /$ serving; however, due to the lower fortification level, losses in whey were analytically undetectable at the level used to produce cheese with $200 \mathrm{IU} /$ serving (Table 2).

The emulsion form of vitamin $\mathrm{D}_{3}$ was used for further retention and long-term stability studies and was added to cheese milk to obtain final fortification levels of 200 and $400 \mathrm{IU} /$ serving $( \pm 6 \% \mathrm{CV}$; Figure 1, bottom panel). Chemical analysis of vitamin $\mathrm{D}_{3}$ in cheese curd and whey showed that up to $90 \%$ of vitamin $\mathrm{D}_{3}$ added to milk was retained in cheese curd at both levels of fortification; the remaining 10\% was found in whey (data not shown). Stability of vitamin $\mathrm{D}_{3}$ in Cheddar cheese during aging was verified by chemical analysis of vitamin $\mathrm{D}_{3}$ levels at $0,3,6$, and 9 mo for Cheddar cheese fortified at 200 and $400 \mathrm{IU} /$ serving. Vitamin $\mathrm{D}_{3}$ content did not change for either fortification level from 0 to 9 mo (Figure 1, bottom panel). As vitamin $\mathrm{D}_{3}$ levels were stable across aging, Cheddar cheese appears to be a suitable vehicle for consistent delivery of vitamin $D_{3}$.

The stability of vitamin $\mathrm{D}_{3}$ levels during cheese aging found in this study (Figure 1) is consistent with previous studies (Upreti et al., 2002; Kazmi et al., 2007; Wagner et al., 2008) that had similar results for Cheddar and processed cheeses during shorter times (2 mo or less). In contrast, Banville et al. (2000) found that vitamin $\mathrm{D}_{3}$ levels were reduced during aging. However, the different studies used different methods and sources for vitamin D fortification. Banville et al. (2000) used cream homogenization and liposome encapsulation as the mechanisms to incorporate vitamin $\mathrm{D}$, whereas we used direct homogenization of the vitamin $\mathrm{D}$ emulsion into milk, and others used oil-based and water-based dispersions of vitamin $\mathrm{D}$ or a food-grade emulsification base (Upreti et al., 2002; Kazmi et al., 2007; Wagner et al., 2008). Hence, the contradictory results from the study of Banville et al. (2000) are likely due to the vitamin $\mathrm{D}_{3}$ being more exposed to physicochemical and microbial factors attributable to differences in forms of vitamin $\mathrm{D}_{3}$ used between the studies.

We further tested the sensory acceptability of vitamin $\mathrm{D}_{3}$-fortified Cheddar cheese by consumer taste panels and sensory attributes by descriptive panels. A consumer preference taste panel was conducted on vitamin $\mathrm{D}_{3}$-fortified Cheddar cheese at 3, 6, and 9 mo. At 3 mo, no difference $(P=0.4)$ was observed in mean liking scores between the control and fortified cheeses

Table 2. Recovery of vitamin $\mathrm{D}_{3}$ in curd and loss in whey during standard Cheddar cheese manufacture from $136 \mathrm{~kg}$ of milk fortified with a vitamin $\mathrm{D}_{3}$ emulsion (values are reported as mean $\pm \mathrm{SD}$ )

\begin{tabular}{|c|c|c|c|c|c|c|}
\hline \multirow[b]{2}{*}{ Sample } & \multicolumn{3}{|c|}{$\begin{array}{l}\text { Vitamin } D_{3} \text { fortification level } \\
\quad(\mathrm{IU} / 100 \mathrm{~g})(\mathrm{n}=2)\end{array}$} & \multicolumn{3}{|c|}{$\begin{array}{c}\text { Vitamin } \mathrm{D}_{3} \text { recovered/lost } \\
(\%)(\mathrm{n}=2)\end{array}$} \\
\hline & $0 \mathrm{IU} /$ serving & $200 \mathrm{IU} /$ serving & $400 \mathrm{IU} /$ serving & $0 \mathrm{IU} /$ serving & $200 \mathrm{IU} /$ serving & $400 \mathrm{IU} /$ serving \\
\hline Curd & ND & $758 \pm 72.1$ & $1,363.5 \pm 78.5$ & ND & $87.0 \pm 9.1$ & $89.1 \pm 1.2$ \\
\hline Whey & ND & ND & 16.1 & ND & ND & $11.7 \pm 0.4$ \\
\hline
\end{tabular}

${ }^{1} \mathrm{ND}=$ not detected. 

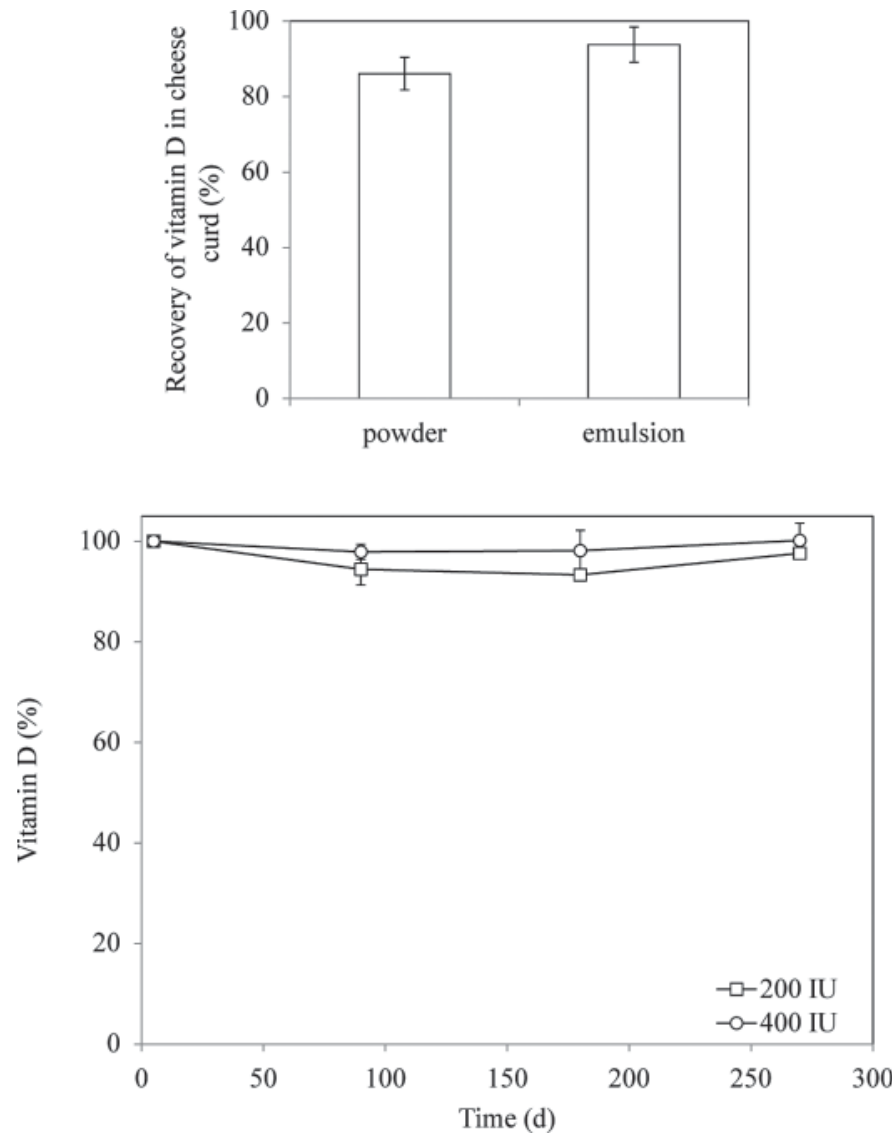

Figure 1. Recovery (\%) from powder and emulsified vitamin D sources fortified to a final level of $400 \mathrm{IU}$ (top panel) and retention of vitamin $\mathrm{D}_{3}$ (emulsion form; $\%$ of level at $5 \mathrm{~d}$ ) in Cheddar cheese (made from $113 \mathrm{~kg}$ of milk) during aging.

(Figure 2). Further consumer preference taste panels conducted on 6- and 9-mo-old fortified Cheddar cheese verified the lack of any difference $(P \geq 0.2)$ in scores between the unfortified and fortified cheeses. Another study that conducted sensory evaluation of vitamin $\mathrm{D}_{3^{-}}$ fortified process cheese at 2 mo (Upreti et al., 2002) also found no differences due to fortification but did not evaluate flavor differences during long-term storage. Both vitamin $\mathrm{D}_{3}$-fortified cheeses in our study were equally liked, with an average score above 6 , indicating that they were all liked slightly to moderately overall, and more importantly, not differently from the unfortified cheese.

Descriptive taste panels were conducted at 3,6 , and 9 mo for Cheddar cheese supplemented with vitamin $\mathrm{D}_{3}$ at 200 and $400 \mathrm{IU} /$ serving (Figure 3). Among all attributes tested, bitter, salty, and sour tastes were differently $(P=0.01, P<0.001, P<0.001$, respectively $)$ perceived in the 3 -mo-old cheese, whereas bitter, buttery, sour, sweet, and umami flavors were different $(P$ $=0.05, P=0.02, P=0.006, P=0.04$, and $P=0.02$, respectively) at $6 \mathrm{mo}$, and only sour taste was different $(P=0.001)$ at 9 mo. Perception of buttery flavor decreased with increasing vitamin $\mathrm{D}_{3}$ levels in cheese at 3 mo. However, considering that this difference was not noted at 6 or $9 \mathrm{mo}$, the correlation at $6 \mathrm{mo}$ is unlikely to be attributable to vitamin $\mathrm{D}_{3}$ levels. Notably, none of the other flavor differences were correlated to change in vitamin $\mathrm{D}_{3}$ concentrations, suggesting that these flavor differences are probably not linked to the addition of vitamin $\mathrm{D}_{3}$ to cheese. Attributes such as cooked, fishy, fruity, metallic, oxidized, pineappley, rancid, rosy/floral, sulfur, and whey were not detected beyond threshold (score $<0.5$ ) in any of the cheeses. In summary, differences found in Cheddar cheese flavor perception during aging are likely not linked to vitamin $\mathrm{D}_{3}$ addition.

Cheddar cheese flavor is a complex perception of the attributes of various flavor compounds present in the solid matrix (Mulder, 1952; Fox et al., 1995; Fox and Wallace, 1997). The chief compound classes that correlate with acceptable flavor are volatile sulfur com-
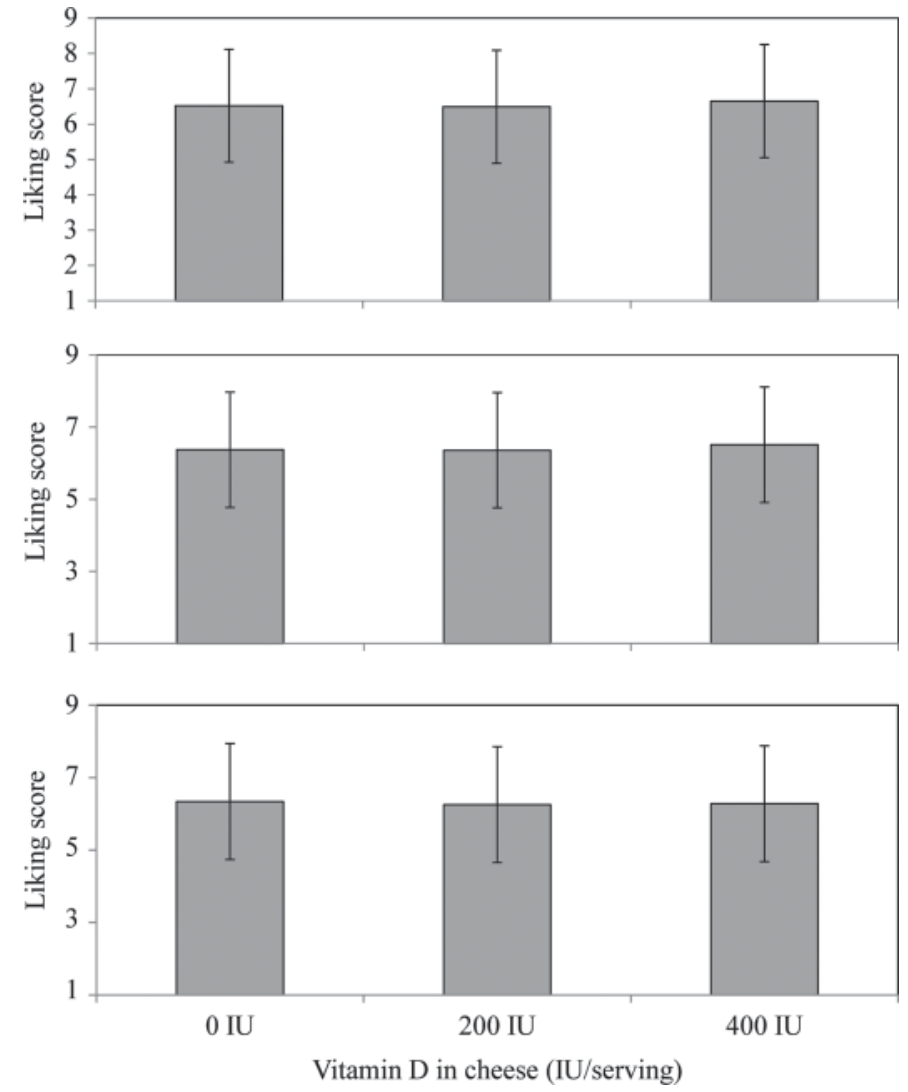

Figure 2. Mean liking scores (y-axis) of a consumer preference taste panel for Cheddar cheese fortified with vitamin $\mathrm{D}_{3}$ at 200 or 400 $\mathrm{IU} /$ serving and the nonfortified control cheese (x-axis) at 3 mo (top panel), 6 mo (middle panel), and 9 mo (bottom panel). Error bars show standard deviations in liking scores of the entire set of panelists. 

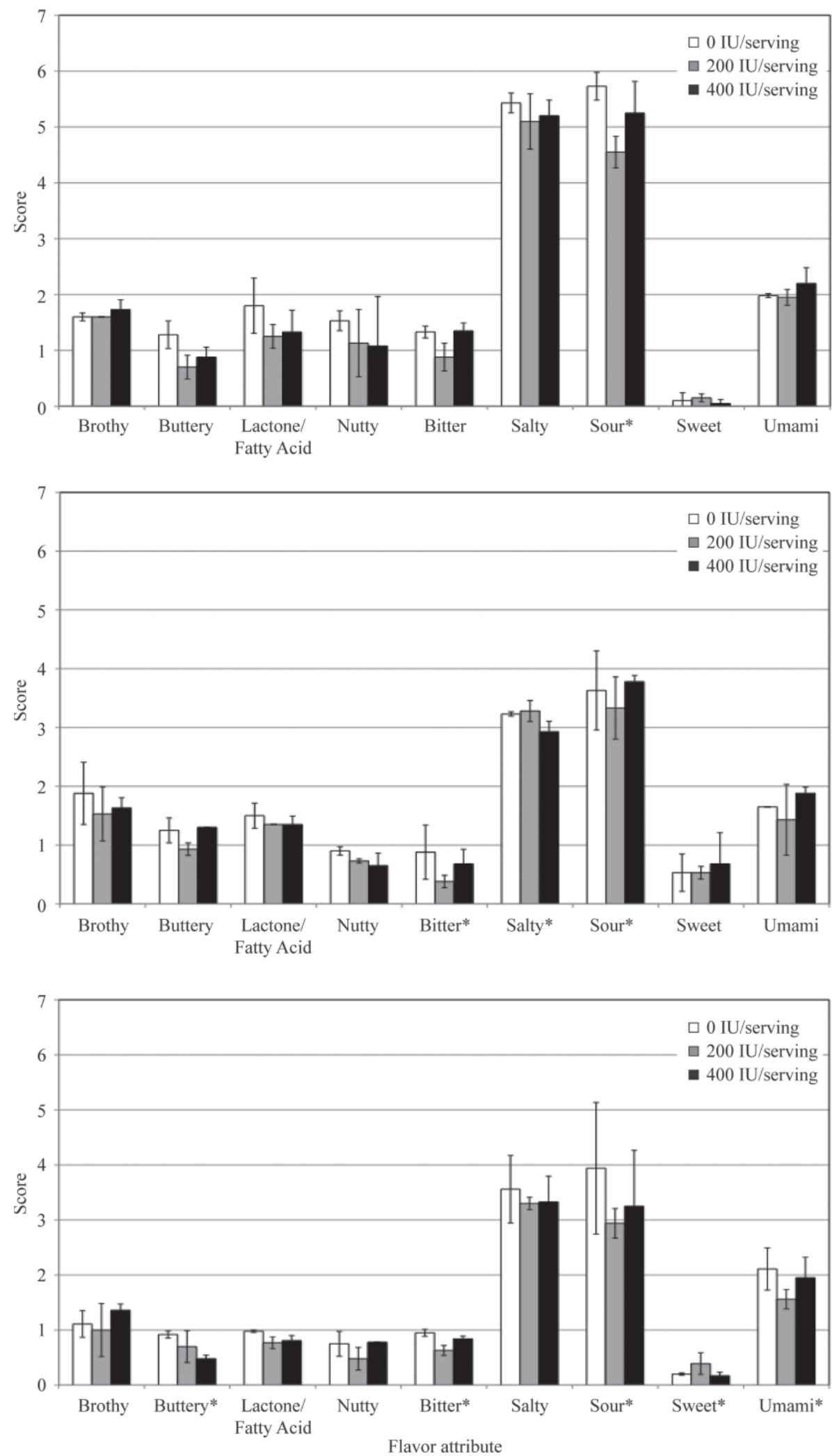

Figure 3. Mean attribute scores for Cheddar cheese fortified with vitamin $\mathrm{D}_{3}$ at 0 (control), 200, and $400 \mathrm{IU} / \mathrm{serving}$ at 3 (top), 6 (middle), and 9 mo (bottom panel) of age. Attributes different $(P \leq 0.05)$ between samples are indicated by an asterisk $(*)$. Attributes tested but not detected beyond threshold (score $<0.5$ ) were cooked, fishy, fruity, metallic, oxidized, pineappley, rancid, rosy/floral, sulfur, and whey. Error bars show standard deviations in liking scores of the entire set of panelists across 2 replicates. 
pounds and branched-chain fatty acids that provide a rich, nutty flavor at low concentrations (Ganesan et al., 2007; Ganesan and Weimer, 2007). Other flavors such as rosy/floral, fruity, or pineappley are considered off-flavors and are attributed to metabolism of aromatic amino acids by starter bacteria (Gao et al., 1997), whereas metallic, oxidized, and fishy off-flavors link to oxidative degradation of lipids in cheese, which increases the concentration of free fatty acids (Ganesan et al., 2007). Addition of vitamin D may either enhance or mask the perception of these flavors by unknown mechanisms or enhance or reduce microbial enzyme activity toward flavor compound generation. Our descriptive analysis was targeted to study the effect of vitamin D toward augmentation of acceptable flavor attributes and reduction of off-flavor. We found that addition of vitamin $\mathrm{D}$ did not correlate to development of either flavor type.

\section{CONCLUSIONS}

Cheddar cheese can be fortified with vitamin $\mathrm{D}_{3}$ by adding vitamin $\mathrm{D}_{3}$ emulsion into a portion of cheese milk, with approximately $90 \%$ being retained in the cheese. No decrease in vitamin $\mathrm{D}_{3}$ in the cheese occurred during 9 mo of storage, and at 3,6, and 9 mo no difference was perceived in sensory attributes between the control unfortified cheese and cheese containing 200 or $400 \mathrm{IU} /$ serving. Cheese makers can incorporate vitamin $\mathrm{D}_{3}$ in Cheddar cheese by adding the emulsion form to the cheese milk with or without homogenization, with no alterations to flavor due to the fortification.

\section{REFERENCES}

AOAC. 2006. Official Methods of Analysis. Vol. I and II. 18th ed. Association of Official Analytical Chemists Gaithersburg, MD.

Banville, C., J. C. Vuillemard, and C. Lacroix. 2000. Comparison of different methods for fortifying Cheddar cheese with vitamin D. Int. Dairy J. 10:375-382.

Bikle, D. D. 1997. Vitamin D: A calciotropic hormone regulating calcium-induced keratinocyte differentiation. J. Am. Acad. Dermatol. 37:S42-S52.

Boland, R. L. 1986. Plants as a source of vitamin $\mathrm{D}_{3}$ metabolites. Nutr. Rev. 44:1-8.

Bouillon, R., G. Eelen, L. Verlinden, C. Mathieu, G. Carmeliet, and A. Verstuyf. 2006. Vitamin D and cancer. J. Steroid. Biochem. Mol. Biol. 102:156-162.

Ceglia, L. 2009. Vitamin D and its role in skeletal muscle. Curr. Opin. Clin. Nutr. Metab. Care 12:628-633.
Fox, P. F., T. K. Singh, and P. L. H. McSweeney. 1995. Biogenesis of flavour compounds in cheese. Chemistry of Structure-Function Relationships in Cheese. Plenum Press, New York, NY.

Fox, P. F., and J. M. Wallace. 1997. Formation of flavour compounds in cheese. Adv. Appl. Microbiol. 45:17-85.

Ganesan, B., M. C. Qian, H. M. Burbank, and B. C. Weimer. 2007 Compounds associated with cheese flavor. Pages $26-55$ in Improving the Flavour of Cheese. B. C. Weimer, ed. Woodhead/CRC Press, Cambridge, UK.

Ganesan, B., and B. C. Weimer. 2007. Amino acid metabolism in relationship to cheese flavor development. Pages 70-101 in Improving the Flavour of Cheese. B. C. Weimer, ed. Woodhead/CRC Press, Cambridge, UK.

Gao, S., D. H. Oh, J. R. Broadbent, M. E. Johnson, B. C. Weimer, and J. L. Steele. 1997. Aromatic amino acid catabolism by lactococci. Lait 77:371-381.

Hanley, D. A., and K. S. Davison. 2005. Vitamin D insufficiency in North America. J. Nutr. 135:332-337.

Holden, J. 2009. USDA national nutrient database. Accessed May 16, 2011. http://www.nal.usda.gov/fnic/foodcomp/search/.

Holick, M. F. 1995. Defects in the synthesis and metabolism of vitamin D. Exp. Clin. Endocrinol. Diabetes 103:219-227.

Holick, M. F. 2007. Vitamin D deficiency. N. Engl. J. Med. 357:266281.

Institute of Medicine. 2010. Dietary Reference Intakes for Vitamin D and Calcium. http://www.iom.edu/Activities/Nutrition/DRIVitDCalcium.aspx.

Institute of Medicine, Food and Nutrition Board. 1999. Dietary Reference Intakes for Calcium, Phosphorus, Magnesium, Vitamin D, and Fluoride (Dietary Reference Intakes). National Academies Press, Washington, DC.

Institute of Medicine, Food and Nutrition Board. 2009. Dietary reference intakes for calcium and vitamin D. Accessed May 9, 2011. http://www.iom.edu/Reports/2010/Dietary-Reference-Intakesfor-Calcium-and-Vitamin-D.aspx.

Kazmi, S. A., R. Vieth, and D. Rousseau. 2007. Vitamin D3 fortification and quantification in processed dairy products. Int. Dairy J. 17:753-759.

Martini, S., J. E. Thurgood, C. Brothersen, R. Ward, and D. J. McMahon. 2009. Fortification of reduced-fat Cheddar cheese with n-3 fatty acids: Effect on off-flavor generation. J. Dairy Sci. 92:18761884 .

Mulder, H. 1952. Taste and flavour forming substances in cheese Neth. Milk Dairy J. 6:157-167.

Upreti, P. V. V. Mistry, and J. J. Warthesen. 2002. Estimation and fortification of vitamin D3 in pasteurized process cheese. J. Dairy Sci. 85:3173-3181.

US FDA. 2007. 21CFR101.9. Nutrition Labeling of Food. Accessed May 9, 2011. http://edocket.access.gpo.gov/cfr_2007/ aprqtr/21cfr101.9.htm.

Vieth, R., H. Bischoff-Ferrari, B. J. Boucher, B. Dawson-Hughes, C. F. Garland, R. P. Heaney, M. F. Holick, B. W. Hollis, C. LambergAllardt, J. J. McGrath, A. W. Norman, R. Scragg, S. J. Whiting, W. C. Willett, and A. Zittermann. 2007. The urgent need to recommend an intake of vitamin $\mathrm{D}$ that is effective. Am. J. Clin. Nutr. 85:649-650

Wagner, D., D. Rousseau, G. Sidhom, M. Pouliot, P. Audet, and R. Vieth. 2008. Vitamin $\mathrm{D}_{3}$ fortification, quantification, and longterm stability in Cheddar and low-fat cheeses. J. Agric. Food Chem. 56:7964-7969. 